6-2012

Increasing Children's Consumption of Fruit and Vegetables: Does the Type of Exposure Matter?

Chelsea Osborne

Catherine A. Forestell

Follow this and additional works at: https://scholarworks.wm.edu/aspubs

Part of the Child Psychology Commons 


\section{Highlights}

Increasing children's consumption of fruit and vegetables: Does the type of exposure matter?

Chelsea L. Osborne, Catherine A. Forestell *

The College of William and Mary, Williamsburg, VA 23185, United States

$\checkmark$ Children were exposed to food variety or to books about healthy eating. $\triangleright$ Exposure to food or books increased acceptance of fruit. $>$ Parental pressure to eat was negatively associated with increased fruit acceptance. $\$$ Children who were exposed to books ate more of an infrequently consumed fruit. Neither food nor book exposure affected children's acceptance of familiar vegetables. 


\title{
Increasing children's consumption of fruit and vegetables: Does the type of exposure matter?
}

\author{
Q13 \\ Chelsea L. Osborne, Catherine A. Forestell *
}

The College of William Mary, Williamsburg, VA 23185, United States

\section{A R T I C L E I N F O}

\section{Article history:}

Received 16 October 2011

Received in revised form 4 January 2012

Accepted 5 January 2012

Available online $\mathrm{xxxx}$

$$
\begin{aligned}
& \text { Keywords: } \\
& \text { Fruit } \\
& \text { Vegetable } \\
& \text { Information } \\
& \text { Children } \\
& \text { Food preference } \\
& \text { Repeated exposure }
\end{aligned}
$$

\begin{abstract}
A B S T R A C T
This study sought to determine how eight days of home exposure to information about healthful foods and 22 eating behaviors in the form of children's books and a variety of fruit and vegetables interacted to affect 4- 23 to 8-year-old children's $(N=59)$ consumption of fruit and vegetables. Before and after the home exposure, 24 children participated in a task in which their consumption of a variety of fruit and vegetables, which ranged 25 in familiarity; was measured. Results indicated that exposure to food and books were both effective at in- 26 creasing consumption of fruit, but not vegetables. Additionally, children who were exposed to books con- 27 sumed more of an infrequently consumed fruit presented during the post-test, but only if they had not 28 been exposed to food during the home exposure. Overall children's fruit consumption increased more if 29 their mothers did not pressure them to eat and those who were less neophobic were more likely to try a 30 novel fruit or vegetable during the post-test. These findings suggest that information and food variety 31 be effective for increasing acceptance of fruit, and highlights the need for more research that investi- 32 gates the efficacy of intervention strategies that promote vegetable consumption in young children.
\end{abstract}

(c) 2012 Published by Elsevier Inc. 34
In order to maintain a healthful diet, adults should consume between 2.5 and 6.5 cups [1] or at least 5 portions of a variety of fruits and vegetables each day [2] to maintain a healthy diet. Diets that are rich in fruit and vegetables have been shown to reduce the risk of chronic disease and various cancers [3,4]. However, despite these health benefits, many adults fail to consume enough fruit and vegetables to meet daily dietary recommendations. Given that children, like adults have unhealthy eating patterns [5-7], it is not surprising approximately $32 \%$ of children and adolescents are overweight or obese [8]. Because consumption of fruit and vegetables helps to protect against obesity [9], it is of imminent importance to develop better strategies to increase children's willingness to consume these healthful foods.

As most parents and caregivers are aware, increasing children's consumption of fruit and vegetables can be challenging. Children are born with a genetic predisposition to prefer sweet and to avoid bitter foods such as green leafy vegetables [10,11]. It has been hypothesized that this predisposition evolved to attract children to energy-dense foods while discouraging consumption of toxins $[13,14]$. Although this may have enhanced survival in environments that were historically characterized by food scarcity, it is clearly maladaptive in our obesogenic environment.

Another barrier to healthy eating is neophobia; defined as a reluctance to try unfamiliar foods $[15,16]$. This hesitancy to eat unfamiliar

\footnotetext{
* Corresponding author at: Department of Psychology, College of William and Mary, P.O. Box 8795, Williamsburg, VA 23187-8795, United States. Tel.: +1 7572213892. E-mail address: caforestell@wm.edư (C.A. Forestell).
}

foods rises dramatically around two years of age and then decrease 63 gradually $[17,18]$. Neophobia has been shown to predict food variety 64 in children's diets, with neophobic children trying and liking fewer 65 foods, and consuming fewer calories than their less neophobic peers 66 [19-21]. According to Wardle et al. [5], neophobia accounts for 5.5\% 67 of the variance in children's fruit and vegetable consumption. High 68 levels of neophobia tend to be associated with lower frequency of 69 consumption of fruit and vegetables, but not sweet, fatty, or starchy 70 foods [22]. In an attempt to promote children's fruit and vegetable in- 71 take, parents often resort to various controlling and coercive feeding 72 strategies, such as providing rewards for eating disliked foods (e.g. 73 "If you finish your vegetables, you can have dessert"). Although this 74 approach may encourage children to eat an undesired food (thereby 75 potentially combating neophobia), it ultimately reduces liking for 76

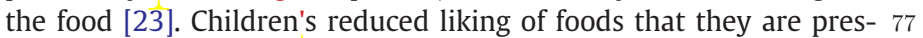
sured to eat; is thought occur through associations formed between 78 the food and the negative emotions experienced during the eating ep- 79 isode $[24,25] . \Omega$

A strategy trat has been shown to be more effective for increasing 81 children's liking of healthful foods is repeated exposure to these foods 82 [26-28] âs well as exposure to a variety of healthful foods [29]. Howev- 83 er, from a practical perspective these strategies may have limited effica- 84 cy. That is, as parents become frustrated with their children's continued 85 resistance to try new or disliked foods they may discontinue exposing 86 them, thereby limiting the variety of foods the child experiences [30]. 87 As a result, children's experience with healthful foods may be limited 88 to visual exposure; and/or to information about their healthfulness 89 (e.g., "You should eat this because it is good for you"). 
Although children gain information about healthy eating from a variety of sources at home and at school [e.g., 31] and acquire welldeveloped schemas about healthy eating [32], there is evidence suggesting that information, or visual exposure to foods alone may not be effective for increasing children's liking and consumption of healthful foods [e.g. 27,28]. There are several factors that may explain this. First, although children understand that nutritious food contributes to a healthy body, they are generally not concerned about their health [33] and second, children appear to believe that healthful foods are unpalatable [34].

However, more recent work suggests that toddlers who are repeatedly exposed to pictures of fruit and vegetables may learn to preferentially attend to these foods relative to other unexposed foods [35]. It appears that this enhanced interest in the appearance of the exposed foods eventually reduces their reluctance to taste them [36]. The present study sought to extend this work by determining whether exposure to pictures of healthful foods and information about healthy eating would affect children's consumption of fruit and vegetables to the same extent as exposure to a variety of healthful foods. Towards this aim, we tested children's willingness to consume a variety of fruits and vegetables before and after a homeexposure phase in which they were exposed to several different fruits and vegetables and/or children's books that depicted fruit and vegetables and discussed healthy eating in a repeated measures design. A secondary goal of the current study was to determine whether individual differences in mothers' feeding style and children's neophobia mediated changes in consumption of the foods from pre- to post-test.

Based on previous research that has shown that repeated exposure to foods and variety is effective for increasing children's acceptance of foods [e.g. 28,29], we hypothesized that exposure to a variety of foods would increase children's consumption of the test foods. Based on recent work by Houston-Price et al. [36], we additionally predicted that exposure to books that depicted healthful foods would increase children's acceptance of the foods. Finally we predicted that children whose mothers pressured them to eat healthful foods would increase their intake of the foods less than those with mothers who did not pressure their children to eat [24,25], and children with higher levels of neophobia would consume less food during the pre- and post-tests [22].

\section{Methods}

\subsection{Participants}

Fifty mothers and their 64 four-to eight-year-old children (mean age $=6.01 \pm 0.17$ years) were recruited through advertisements placed in local newspapers, flyers, and mass mailings throughout the region. Children with food allergies or those taking medication that suppressed their appetite were not eligible for participation.

\subsection{Design}

Each mother-child pair agreed to participate in a 10-day experimental study. Childrên were tested individually one day before (Day 1 ) and the day after (Day 10) an eight-day home exposure period. On both test days children were exposed to a free-eating task, which we called a "buffet". During this task they were offered a variety of fruit and vegetables and given the opportunity to eat as long as they wished. Each motherchild pair was randomly assigned to one of four experimental groups using a $2 \times 2$ between-subjects design according to a predetermined group list which was created with a random number generator. Groups differed according to whether they received books and/or food during and 8-day home exposure period. That is, for half of the participants, mothers were sent home with books to read to their children each day, and approximately half of the mothers within each of these groups received four fruits and four vegetables to feed to their children each day. Thus the following four groups were created: Group F (food expo- 152 sure only), Group B (book exposure only), Group F-B (food and book ex- 153 posure), and Group C (the control group which received neither book 154 nor food exposure). The College of William \& Mary Protection of 155 Human Subjects Committee approved all procedures. Informed consent 156 was obtained from each mother and assent was obtained from each 157 child over eight years of age.

\subsection{Test stimuli}

\subsubsection{Buffet foods}

On Day 1, children were presented with six foods during the buffet: 161 apple, banana, orange, broccoli, baby carrots, and red pepper. These 162 foods were chosen because they are commonly consumed uncooked in 163 their natural form. The foods were held in individual clear rectangular 164 plastic containers (approximately $13 \mathrm{~cm} \times 7 \mathrm{~cm} \times 7 \mathrm{~cm}$ ) in two larger 165 clear plastic bins with flip-up lids (approximately $38 \mathrm{~cm} \times 13 \mathrm{~cm} \times 166$ $10 \mathrm{~cm}$ ), one for fruit and one for vegetables. All foods were presented 167 raw, in bite-size portions, and filled the plastic containers halfway to 168 three-fourths to the top. The position of the fruits and vegetables in 169 each of the bins was randomized and the bin facing the child was counter- 170 balanced. On Day 10, children were again presented with the original six 171 foods. Additionally they were presented with two new fruits and two new 172 vegetables, which their mothers reported were infrequently consumed 173 on Day 1 during the food frequency interview (Table 2). The two fruits 174 were chosen from kiwi, papaya, starfruit, or another tropical fruit (quince, 175 or ugli fruit) and the vegetables were chosen from snap peas, baby corn or 176 water chestnuts. For each child, we chose one fruit and vegetable that was 177 completely novel (hereafter referred to as Day 10-Novel) to the child, 178 whereas the other fruit and vegetable had been consumed before (Day 179 10 previously ensumed, hereafter referred to as Day 10-PC). Thus, on 180 Day 1 and 10, three fruits and three vegetables were presented. Addition- 181 ally on Day 10 only, two relatively unfamiliar fruits and two relatively un- 182 familiar vegetables were presented alongside the familiar foods for a total 183 of 10 foods.

\subsubsection{Home exposure foods}

185

Children took home four fruits and four vegetables that were each 186 to be consumed on separate days between Days 2-8. For each child, 187 foods were randomly chosen from the following: apple, banana, or- 188 ange, blueberries, pineapple, papaya, baby carrots, broccoli, sweet 189 pepper, cauliflower, celery, baby corn, and snap peas, with the limita- 190 tion that two of the fruits and two of the vegetables were foods that 191 had not been presented during the buffet. Apples, oranges, and ba- 192 nanas were sent home whole and uncut and the remaining foods 193 were in bite-size pieces. Each food was sent home in pre-weighed, 194 clear quart-size plastic, sealed freezer bag, with a label that indicated 195 the date on which the contents of that particular bag should be fed. 196 The order in which the foods were assigned was randomized accord- 197 ing to a random number generator.

\subsubsection{Home exposure books}

199

Children in Groups B and F-B brought home two books; one of 200 which focused on healthy eating habits (Eat Healthy, Feel Great [37]) 201 and another which identified more than 70 colored drawings of 202 fruit and vegetables, from the everyday apple to the jicama (Eating 203 the Alphabet [38]).

\subsection{Questionnaires and interviews}

\subsubsection{Child Food Frequency Interview}

206

Mothers were asked to indicate whether their child ever tried 207 each of the foods presented during the home exposure and the buffet, 208 as well as a wide array of other fruit and vegetables, and if so, the fre- 209 quency with which they consumed each of these foods per day, week, 210 month, or year. 


\subsubsection{Food Neophobia Questionnaire}

All mothers completed a 10-item scale that measured their own approach and avoidance of novel foods [ 17$\}$ in which they responded on a seven-point Likert scale from "extremely disagree" (1) to "extremely agree" (7). Pliner and Hobden [16] reported good internal consistency (Cronbach's alpha coefficient of 0.88 ) and satisfactory test-retest reliability for this test.

\subsubsection{Mother's perceptions of their child's temperament and food neophobia}

Mothers also completed a 25-item scale that measured aspects of their child's temperament [39]. Dimensions included emotionality, shyness, activity, sociability, neophobia, and negative reactivity to food. The last two subscales were of primary interest in the present study. Scores for each of the dimensions could range from 1 to 5 , with higher scores indicating "more" of that particular temperament characteristic. This questionnaire has been shown to have satisfactory internal and test-retest reliabilities [39].

\subsubsection{Maternal Child-feeding Style Questionnaire}

The mothers' child-feeding practices and their perception of their children's risk for overweight were assessed by using the Child-Feeding Questionnaire (CFQ) [40]. This questionnaire consists of six subscales; restriction, which is the extent to which mothers control how much, when, and what their child eats; monitoring, which assesses the extent to which mothers keep track of what their child eats; pressure to eat, which is mothers' tendency to pressure their child to eat more food. Additional subscales include perceived child's weight (mothers' perceptions of their child's weight history), perceived parent's weight mothers' perceptions of her own weight history, (which was not reported in the present paper) and concern about child's weight (mothers' concern about their child's risk of becoming overweight). Previous analyses of this sample provided evidence of acceptable internal consistency and criterion validity for the Child Feeding Questionnaire subscales [40].

\subsection{General procedure}

Each mother brought cheir child for approximately $1 \mathrm{~h}$ to the laboratory on Days 1 and 10 of the experiment. To minimize the effect of satiation, they were asked not to feed their child for at least $1 \mathrm{~h}$ before 248 arriving at the laboratory. All mothers complied with this request; on 249 average children were last fed $3 \mathrm{~h}$ before arriving on both test days 250 (Table 1). On each day, children participated individually in the buffet 251 task while their mother interviewed and completed a variety of 252 questionnaires about their child's eating habits and child-feeding 253 practices in a separate room as described below.

\subsubsection{Laboratory testing} with only the experimenter present. On Day 1, each child was seated 257 at a small table and asked if they had ever eaten at a buffet. They were 258 reminded that at a buffet they could eat as little or as much of any of 259 the foods they wanted. The buffet foods were presented in clear 260 translucent plastic bins in front of the child on the table. On both 261 test days children were asked to walk around the table so that they 262 could look at each of the foods within the bins. Children were then 263 given a plate and told they could begin selecting the foods they 264 would like to eat. Children were allowed to eat until they indicated 265 that they were finished. All food that was left on their plate was 266 returned to the appropriate bin, and each food was weighed.

\subsubsection{Home exposure period}

268

Mothers who received books were asked to read one to their child 269 each day in alternation over the eight-day home exposure period. 270 Mothers who received food were asked to offer their children one 271 fruit or vegetable per day in the assigned order (as described above) 272 when their child was hungry. Children were given one opportunity to 273 eat the assigned food each day. If the child refused the food, mothers 274 were asked to present it again later that day. All mothers in Groups F, 275 F/B and B were asked to keep a log of the foods that their children con- 276 sumed each day. Mothers froze and returned the remaining food (in- 277 cluding skin and peels that were not consumed) on Day 10 in their 278 original sealed freezer bags. Each bag was dried off to remove any con- 279 densation and weighed after each session to determine intake.

\subsection{Statistical analyses}

Children's consumption of the buffet and home exposure foods was 282 determined by calculating the difference between pre- and post-weight 283

Table 1

Mother and child characteristics.

\begin{tabular}{|c|c|c|c|c|c|}
\hline & \multicolumn{2}{|l|}{ Food } & \multicolumn{2}{|l|}{ No food } & \multirow[t]{2}{*}{ Total } \\
\hline & Book & No book & Book & No book & \\
\hline Children, $n$ & 12 & 14 & 18 & 15 & 59 \\
\hline Sex $(\%$ female $)$ & 75.0 & 35.7 & 50.0 & 40.0 & 49.2 \\
\hline Age, mean \pm SEM, mo & $71.8 \pm 4.9^{\mathrm{a}}$ & $67.4 \pm 4.7$ & $76.2 \pm 3.6$ & $73.5 \pm 4.3$ & $72.5 \pm 2.2$ \\
\hline $\mathrm{BMI}$, mean $\pm \mathrm{SEM}, \mathrm{kg} / \mathrm{m}^{2}$ & $16.3 \pm 1.0$ & $15.9 \pm 0.6$ & $15.9 \pm 0.4$ & $15.5 \pm 0.3$ & $15.9 \pm 0.3$ \\
\hline \multicolumn{6}{|c|}{ Temperament; mean scores for each subscale range from 1 to 5 . } \\
\hline Shyness & $2.7 \pm 0.3^{-}$ & $2.2 \pm 0.2$ & $2.0 \pm 0.2$ & $2.4 \pm 0.2$ & $2.3 \pm 0.1$ \\
\hline Emotionality & $3.3 \pm 0.3$ & $2.7 \pm 0.3$ & $3.0 \pm 0.3$ & $3.2 \pm 0.3$ & $3.0 \pm 0.1$ \\
\hline Sociability & $3.6 \pm 0.2$ & $3.6 \pm 0.2$ & $3.8 \pm 0.2$ & $3.7 \pm 0.2$ & $3.7 \pm 0.1$ \\
\hline Activity & $3.9 \pm 0.3$ & $3.9 \pm 0.2$ & $4.1 \pm 0.2$ & $4.0 \pm 0.2$ & $4.0 \pm 0.1$ \\
\hline Negative reactions to foods & $3.1 \pm 0.3$ & $2.6 \pm 0.3$ & $2.8 \pm 0.3$ & $3.3 \pm 0.3$ & $3.1 \pm 0.1$ \\
\hline Neophobia & $3.0 \pm 0.3$ & $2.8 \pm 0.3$ & $3.3 \pm 0.3$ & $3.3 \pm 0.3$ & $3.1 \pm 0.1$ \\
\hline Time since last ate (min) & $162.9 \pm 34.2$ & $186.6 \pm 28.0$ & $171.8 \pm 32.9$ & $195.5 \pm 31.7$ & $180.4 \pm 15.4$ \\
\hline \multicolumn{6}{|l|}{ Mothers } \\
\hline Age, mean \pm SEM, y & $37.5 \pm 1.8$ & $34.9 \pm 2.7$ & $33.1 \pm 1.3$ & $33.6 \pm 1.9$ & $34.7 \pm 1.0$ \\
\hline BMI, mean $\pm S E M, k g / \mathrm{m}^{2}$ & $26.2 \pm 1.7$ & $24.9 \pm 1.7$ & $24.4 \pm 1.3$ & $25.4 \pm 1.3$ & $25.2 \pm 0.7$ \\
\hline Years of schooling, mean \pm SEM & $15.5 \pm 0.6$ & $16.6 \pm 0.3$ & $15.7 \pm 0.4$ & $15.3 \pm 0.6$ & $15.8 \pm 0.2$ \\
\hline \multicolumn{6}{|c|}{ Approach to feeding their child, as measured by the CFQ. Mean scores on each subscale range from 1 to 5 . } \\
\hline Restriction & $3.0 \pm 0.3$ & $2.8 \pm 0.3$ & $2.5 \pm 0.2$ & $3.0 \pm 0.3$ & $2.8 \pm 0.1$ \\
\hline Monitoring & $4.0 \pm 0.3$ & $4.0 \pm 0.2$ & $4.0 \pm 0.3$ & $3.6 \pm 0.3$ & $3.9 \pm 0.1$ \\
\hline Pressure to eat & $2.2 \pm 0.3$ & $2.9 \pm 0.3$ & $2.0 \pm 0.2$ & $2.6 \pm 0.3$ & $2.4 \pm 0.1$ \\
\hline Perceived child weight & $3.0 \pm 0.1$ & $2.8 \pm 0.2$ & $3.0 \pm 0.1$ & $3.0 \pm 0.1$ & $2.9 \pm 0.1$ \\
\hline Concern about child's weight & $1.6 \pm 0.3$ & $1.3 \pm 0.1$ & $1.3 \pm 0.1$ & $1.3 \pm 0.1$ & $1.3 \pm 0.1$ \\
\hline
\end{tabular}

a Mean \pm SEM. 
Mothers' reports of their children's daily consumption of the foods presented during the buffet.

and converting the difference to calories (i.e., kcal) for each food-and summed to determine total fruit and total vegetable consumption. To determine whether changes in children's consumption of the buffet foods presented on Days 1 and 10 were a function of the home exposure, we conducted separate three-way repeated Analyses of Variance (ANOVAs) with Book Exp (books vs. no books at home) and Food Exp (food vs. no food at home) as the between-subjects variables and time (Day1 S.Day 10) as the repeated measure. Separate analyses were conductecrurruit and vegetable consumption.

For the Day 10-PC fruit and vegetable that were presented during the buffet-only on Day 10, $2 \times 2$ between-subjects ANOVAs were conducted with type of book exposure (yes, no) and foolexpostre (yes, no) as independent variables. Because many of the children did not try the Day 10-Novel fruit and vegetable, chi-square analyses were performed to determine whether the proportion of children who tried the Day 10-Novel foods differed between groups.

Finally, we conducted a series of correlational analyses to determine whether increases in children's intake during the buffet from Days 1 to 10 ; and their consumption of the new foods on Day 10 were related to their mother's child-feeding style and their food neophobia.

\section{Results}

\subsection{Participant characteristics}

Of the 64 children who were recruited, five were excluded from the final analyses because they did not return for the second test day $(n=3)$; or they did not comply during one of the tasks $(n=2)$. As shown in Table 1, the remaining 59 children ( 29 girls) were randomly assigned to one of four groups, which did not differ in age, sex, BMI, or food neophobia, as reported by their mothers $(p>0.05$ in all cases). Likewise, their mothers $(N=49)$ did not differ in their age, BMI, years of schooling, eating restraint scores, or their reported food neophobia ( $p>0.05$ in all cases). However, mothers whose children were assigned to receive book exposure were more likely to report that they pressured their child to eat on the CFQ $(F(1,55)=4.79$, $p<0.04, \eta^{2}=0.80$ ).

Mothers- reported that their children typically consumed fruit and vegetables approximately once per day (i.e., fruit: $1.49 \pm 0.11$ times/ day; vegetables: $1.32 \pm 0.11$ times/day). Overall, children who ate vegetables less frequently had higher neophobia scores $(r(58)=$ $-0.32, p<0.02)$ and more negative reactions to food $(r(58)=$ $-0.29, p<0.03$ ). As shown in Table 2 , children's regular consumption

\begin{tabular}{lcc}
\hline & $\begin{array}{c}\text { Consumption } \\
\text { (Frequency/Month) }\end{array}$ & \% tried \\
\hline Fruit & & \\
All of the following were presented on Days 1 and 10 & 100 \\
Apple & $13.7 \pm 1.3$ & 100 \\
Banana & $12.7 \pm 1.2$ & 100 \\
Orange & $9.1 \pm 1.7$ & \\
Two of the following were presented on Day 10 only & 78 \\
Kiwi & $1.1 \pm 0.3$ & 25 \\
Papaya & $0.04 \pm 0.1$ & 17 \\
Starfruit (or other tropical fruit) & 0 & \\
& & 100 \\
Vegetables & & 97 \\
All of the following were presented on Days 1 and 10 & 83 \\
Carrot & $8.9 \pm 1.6$ & \\
Broccoli & $4.8 \pm 0.7$ & 61 \\
Sweet pepper & $3.0 \pm 0.9$ & 53 \\
Two of the following were presented on Day 10 only & $1.0 \pm 0.3$ & 35 \\
Sugar snap peas & $0.4 \pm 0.2$ & \\
Baby corn & $0.4 \pm 0.2$ & \\
Water chestnuts & & \\
&
\end{tabular}

of the six buffet foods presented on Days 1 and 10 ranged from 9 to 14324 times a month for fruit and from 3 to 9 times a month for vegetables. 325 For the new fruits and vegetables presented only on Day 10 (i.e., Day 326 10-Novel and Day 10-PC foods), consumption ranged from once a 327 month to never eaten. There were no between-group differences in 328 children's typical daily fruit and vegetable intake; or in their daily in- 329 take of the buffet fruit and vegetables.

\subsection{Food intake and time spent reading during the home exposure phase 331}

As a manipulation check we determined the total amount of time the 332 mothers spent reading to their children from the logs submitted by the 333 mother assigned to Groups B and F-B. Similarly, for the children who 334 took home food (Groups F-B and F), we examined the feeding logs to en- 335 sure that all of the foods were offered on the assigned days; and comput- 336 ed intake. Overall mothers reported reading the books to their children 337 for approximately $100 \mathrm{~min}$ across the eight days, with mean read times 338 varying between 8 and 20 min per day. The children who brought 339 home food consumed more fruit $(267.11 \pm 23.11 \mathrm{~g})$ than vegetables 340 $(73.42 \pm 15.71 \mathrm{~g})$ across the eight days of exposure $(F(1,25)=77.03$. 341 $\left.p<0.001, \eta^{2}=0.76\right)$. However, there were no between group differences 342 in consumption between Group F (fruit: $236.35 \pm 30.79$ g; vegetables: 343 $66.36 \pm 21.75 \mathrm{~g}$ ) and Group F-B (fruit: $303.00 \pm 33.25 \mathrm{~g}$; vegetables: 344 $81.67 \pm 23.49 \mathrm{~g} ; p>0.05$ ). Likewise, while children tried a greater num- 345 ber of fruits ( $3.65 \pm 0.49$ fruits) than vegetables ( $2.88 \pm 1.21$ vegetables $) 346$ during the home exposure, the groups did not differ in the number of 347 fruits and vegetables tried $(p>0.05)$. All mothers reported offering each 348 food on its assigned day.

2.3. Did home exposure increase children's consumption of the foods dur- 350 ing the buffet tasks on Days 1 and 10?

On average children tried $1-2$ of the 3 fruits (i.e., Day $1=2.44 \pm 352$ 0.11 fruits; Day $10=2.11 \pm 0.12$ fruits) and the 3 vegetables (Day 353 $1=1.38 \pm 0.12$ vegetables $_{1}$ Day $10=1.00 \pm 0.11$ vegetables) that 354 were presented on both test days. Groups did not differ in the number 355 of the fruits and vegetables tried. However, analyses of the caloric in- 356 take of the fruit presented on both test days revealed Time $\times$ Food Exp 357 $\left(F(1,55)=5.29, p<0.03, \eta^{2}=0.09\right)$ and Time $\times \operatorname{Book} \operatorname{Exp}(\widehat{F(1,55)}=358$ 4.24, $p<0.05, \eta^{2}=0.07$ ) interactions (Fig. 1A). Simple main effects 359 analyses indicated that those who received books (i.e., Groups F-B 360 and $\mathrm{B})$ showed an overall increase in fruit consumption $(F(1,29)=361$ 5.71, $p<0.03$ ), whereas those who did not receive books did not 362 $(p>0.6)$. Similarly, those who were exposed to foods (i.e., Groups 363 F-B and F) marginally increased their fruit consumption $(F(1,25)=364$ $4.00, p<0.06$ ), whereas those who were not exposed to food did not 365 $(p>0.5)$.

Similar analyses failed to reveal significant group $\times$ time interac- 367 tions for vegetable consumption during the test days. However, as 368 shown in Fig. 1B, children in the book groups consumed more calories 369 of the vegetables on Day 1 than those who were not in the book 370 groups $\left(F(1,55)=, \mathrm{p}<0.05, \eta^{2}=0.09\right)$. Therefore, an additional 2- $371 \mathbf{Q 3}$ way ANCOVA was conducted which included Book exposure and 372 Food exposure as independent variables and caloric consumption of 373 vegetables on Day 1 as a covariate. This additional analysis did not re- 374 veal any main effects of book or food exposure consumption of vege- 375 tables on Day 10.

2.4. Did home exposure increase children's consumption of the Day 10- 377 Novel and Day 10-PC foods?

Marginally more children were willing to try the Day 10-Novel 379 fruit if they brought home books than if they did not (47\% vs. $21 \%$; 380 $\chi^{2}(1)=3.26, p=0.07$ ). For the Day 10-PC fruit; univariate analyses 381 yielded a significant Book Exp $\times$ Food Exp interaction $(F(1,55)=382$ 5.18, $\left.p<0.03, \eta^{2}=0.08\right)$. As shoŵn in Fig. 2, simple main effects 383 

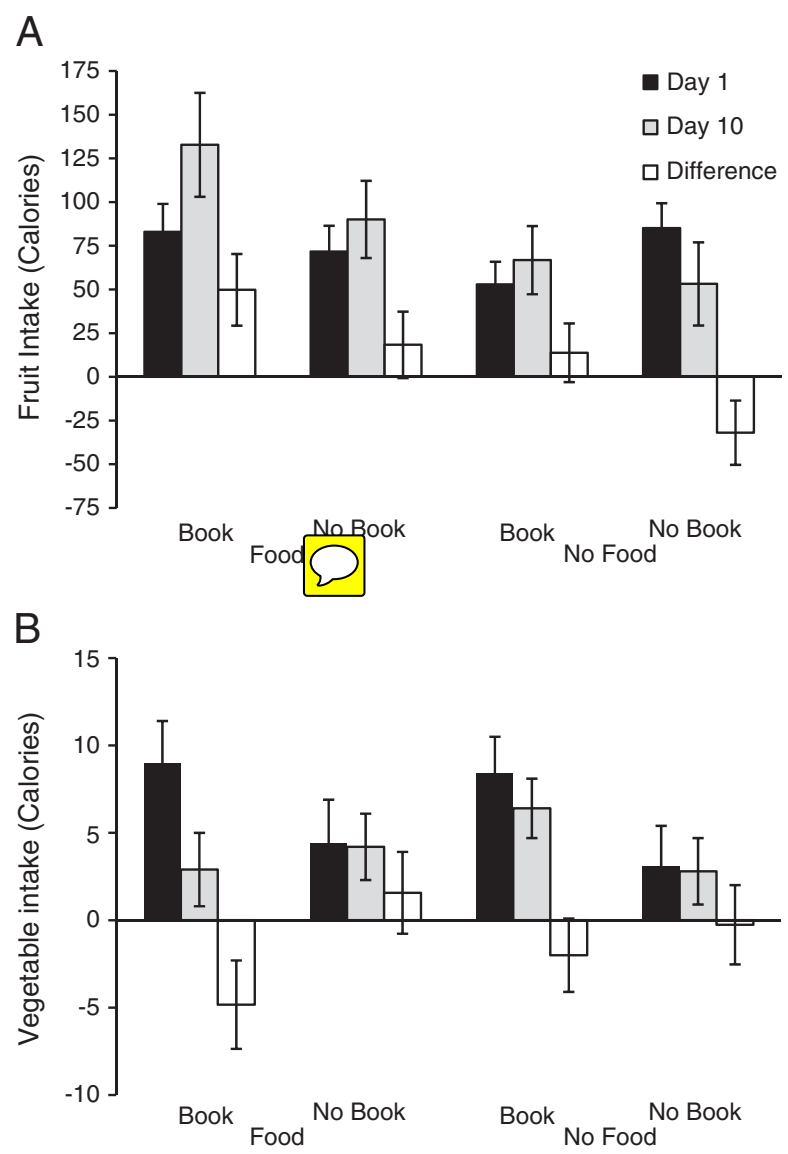

Fig. 1. Caloric intake of the three fruits $(1 \mathrm{~A})$ and three vegetables $(1 \mathrm{~B})$ presented on both Days 1 (black bars) and 10 (gray bars) and differences scores (Day 10 intake minus Day 1 intake). Error bars represent standard error of the mean. The groups differed according to whether they received exposure to books about healthful foods and eating; and whether they received a variety of fruit and vegetables during an 8-day home exposure period. Those who received books significantly increased their fruit intake $(F(1,55)=4.24, p<0.05)$, as did those who received food $(F(1,55)=5.29$, $p<0.03$ ) during home exposure. Vegetable intake did not change as a function of the intervention. (Note difference in the $\mathrm{y}$-axis scale between $1 \mathrm{~A}$ and $1 \mathrm{~B}$ ).

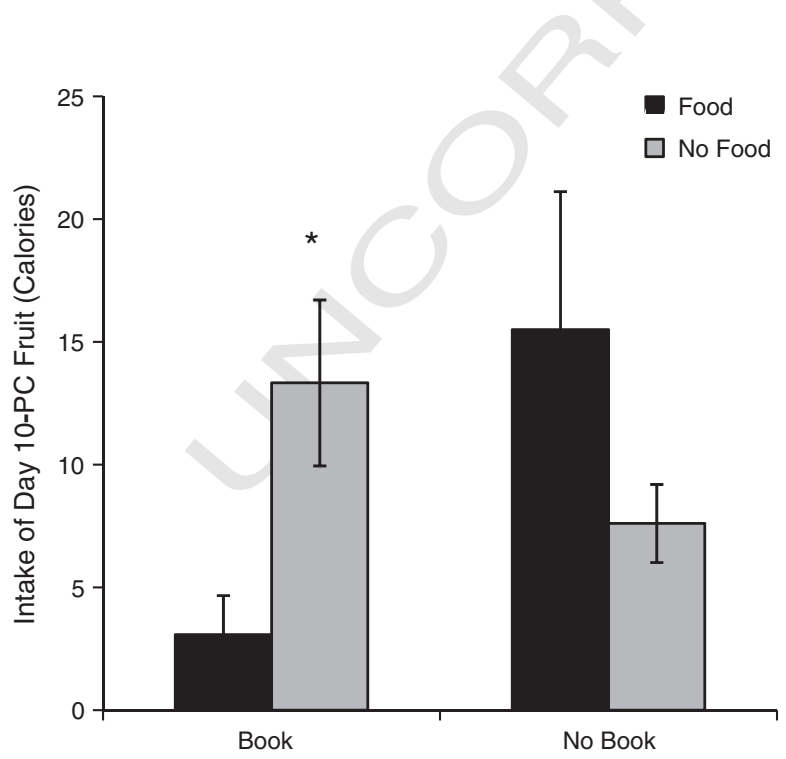

Fig. 2. Children's caloric intake of Day 10-PC fruit (i.e., presented enly on Day 10 only; and previously consumed by the child according to maternal reports) as a function of their home exposure experience. * indicates that for those who were exposed only to books, caloric consumption of the fruit was significantly higher than those who were exposed to both books and food $(p<0.05)$. analyses revealed that children in Group B ate significantly more of 384 the Day 10-PC fruit than those in Group F-B $(F(1,28)=5.52,385$ $p<0.03)$. For children who did not bring home books, consumption 386 of the Day 10-PC fruit did not differ as a function of whether they 387 brought home food $(p>0.25)$. Similar analyses conducted for the 388 Day 10-Novel and PC vegetables failed to yield significant effects of 389 the home exposure regardless of the novelty of the vegetable.

390

2.5. Did Mother's reports of their controlling feeding style and their chi- 391 ld's neophobia affect intake during the buffet?

Children whose mothers reported that they pressured their child 393 to eat showed smaller overall increases in intake of the fruit pre- 394 sented on Days 1 and $10(r(59)=-0.35, p<0.01)$. None of the 395 other CFQ subscales correlated with the children's intake during the 396 buffet tasks. However maternal pressure to eat was negatively corre- 397 lated with mothers' perceptions of their children's weight $(r(59)=398$ $-0.32, p<0.02)$; and the ehild's BMI $(r(59)=-0.30, p<0.03) . \quad 399$

Although neophobia did not correlate with children's increases in 400 food intake from Days 1 to 10, those who tried the Day 10-Novel fruit 401 $(n=21)$ had lower neophobia scores $(2.34 \pm 0.21)$ than those who 402 did not $\left(n=38,3.48 \pm 0.16, F(1,57)=17.82, p<0.01, \eta^{2}=0.24\right)$. A 403 similar difference was also found for those who tried the Day 10- 404 Novel vegetables ( $n=17$, neophobia $=2.47 \pm 0.20$ ) when compared 405 to those who did not try these vegetables $(n=42$, neophobia $=3.32 \pm 406$ $\left.0.20, F(1,57)=7.74, p<0.01, \eta^{2}=0.12\right)$.

\section{Discussion}

In the present study, there was evidence that either exposure to a 409 variety of foods or to food information increased children's accep- 410 tance of commonly consumed fruit. Moreover, children who were ex- 411 posed to food information were more marginally likely to try a novel 412 fruit than were those who were not exposed to information. These 413 findings are consistent with those of Houston-Price et al. [36], who 414 found that exposing toddlers to picture books depicting healthful 415 foods increases consumption of these foods. While the present re- 416 search suggests that some types of information may be as effective 417 as exposure to food variety in increasing children's consumption of 418 fruit, there was no evidence that exposure to information about 419 food and healthy eating habits and food exposure had additive effects. 420 In fact, children who brought home food and books ate less of an in- 421 frequently consumed fruit (Day 10-PC) relative to those who brought 422 home only books. It is possible that exposure to both food and books 423 was "too much of a good thing", causing children to become over- 424 whelmed or disinterested in consuming a food that they have eaten 425 before.

Despite the finding that exposure to food or information appeared 427 to increase fruit acceptance, the results of the current study did not 428 provide any evidence that this exposure increased children's willing- 429 ness to accept vegetables. Although it is possible that important dif- 430 ferences may not have been detected because of small sample sizes 431 which led to insufficient power, our findings suggest that if anything, 432 our manipulation may have done more to decrease rather than in- 433 crease consumption of vegetables. For example, intake of the 3 vege- 434 tables presented on both test days tended to decrease in the food 435 groups. Thus, exposure to a variety of fruits and vegetables while ef- 436 fective for increasing fruit consumption may not necessarily be effec- 437 tive at increasing children's vegetable acceptance. This finding is akin 438 to results reported by [41] who reported that infants failed to increase 439 their consumption of a green vegetable after they had been exposed 440 to a variety of fruits. The authors suggested that this may have oc- 441 curred because the flavor experiences from the palatable fruit offered 442 as part of the home exposure did not generalize to the green 443 vegetable. 
Because vegetable consumption was interspersed with fruit consumption in the present study, a contrast effect may have occurred during home exposure. Through comparison of the palatable home exposure fruit with the less palatable vegetables, the children may have perceived the flavor of the vegetables to be less palatable than they would have been had they been presented alone [42]. Over time, the children who were exposed to food may have learned to associate the fruit with positive flavor sensations; and the vegetables with relatively negative flavor sensations.

Rather than the presence of the fruit in the home exposure phase, it is possible that the absolute number of vegetable exposures was too few to increase vegetable consumption in the test. For example, Pliner [43] gave participants three unfamiliar fruit juices to taste 5,10 or 20 times and found that the number of exposures was positively related to participants' ratings of how much they liked each juice's taste. However, other work has found satiation effects may also occur as a function of these repeated taste exposures, which ultimately leads to dislike of the food [44]. Pliner [43] has suggested that whether repeated exposures actually lead to enhanced liking of the target foods; may be due to participants' initial levels of familiarity with exposed foods. That is, while repeated exposure to unfamiliar foods increases liking, exposure to foods that are already familiar may lead to dislike.

Although other work has reported that children will increase their preference for vegetables after repeated exposure to pictures [36], or to mere exposure to one vegetable or a variety of vegetables [29], these studies have typically either measured children's acceptance of a vegetable presented alone; or with only one or two other foods. In the present study, children's acceptance of vegetables was measured in the presence of several more palatable fruit options, which may have led to the avoidance of the vegetables. It is possible that because fruit is typically consumed as a snack food, whereas vegetables are typically consumed as part of a meal, children may have been less likely to consume the latter during the buffet. Despite this limitation, we would argue that this paradigm more closely approximates situations in which we must choose foods from an array of different items that vary in terms of their palatability. In most cases, however, we must choose from a wider variety of foods which vary not only in palatability, but also nutritional and caloric content.

Our results also indicate that additional factors may mediate the effectiveness of food and exposure to information. While various strategies might serve to increase children's consumption of fruit and, in some cases vegetables, their effectiveness will vary depending on the child's personal characteristics and the environment. In this study, those with higher neophobia scores were less likely to try the new novel foods on Day 10. Moreover those whose mothers indicated that they pressured them to eat were less likely to increase their fruit consumption. Although it has been assumed that parental pressure to eat is a cause of children's poor eating habits [45,46], more recent research suggests that the causal pathway may be reversed; with parental pressure to eat is occurs in response to perceptions of their children's weight $[47,48]$. Indeed, in the current study, mothers who pressured their children to eat may have done so because of their awareness of their children's lower BMIs. Regardless of the causal direction of this relationship, it is important to remember that strategies to increase consumption of healthful foods may be less effective in this subset of children.

The results of the current study suggests that repeated exposure, whether it is in the form of flavor exposures or information about healthful foods and healthy eating habits, may be a promising strategy for improving children's liking of fruit. Although most two to three year-old children consume recommended amounts of total fruit, older children fail to meet these recommendations. Of the fruit that they do consume, more than half is in the form of juice [49], which lacks dietary fiber and contributes extra calories. Thus, it appears that these findings could have important real-world application after further investigation to answer the following important questions. First, although the present study, in combination with 511 work by Houston-Price et al. [35,36], demonstrates increased accep- 512 tance of familiar and unfamiliar fruit as a function of information, 513 the underlying mechanisms of change remain unclear. Whether this 514 increase in acceptance occurred as a function of enhanced interest 515 in the foods and healthy eating [50] is a topic for further investigation. 516 Second, in order for these interventions to be truly effective, it is im- 517 portant to demonstrate whether exposure to information and food 518 variety produced long-term changes in acceptance. Finally, more re- 519 search is needed to determine how to increase children's willingness 520 to consume vegetables in the presence of more palatable food op- 521 tions, which is a challenge that faces most children and adults on a 522 daily basis.

Because obese children tend to become obese adults [51,52] with 524 greater risk of adult morbidity and mortality $[9,53]$, it is of primary 525 importance to develop effective strategies to prevent the develop- 526 ment of unhealthy eating styles. In order to reach this goal, future re- 527 search should focus on understanding the long-term implications of 528 various interventions in order to provide effective evidence-based 529 strategies for developing healthy eating habits in our children; a gen- 530 eration which will struggle with the effects of obesity.

\section{Uncited reference}

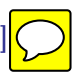

\section{Acknowledgments}

This work was funded, in part, by an HHMI undergraduate sum- 535

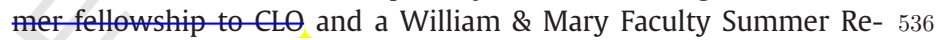
search Grant to CAF. We would like thank the following individuals 537 for their excellent technical assistance: Nicole Karcher, Kristin Rear- 538 don, Sarah Brooks, and Kelsey Otton.

\section{References}

[1] U.S. Department of Agriculture, U.S. Department of Health and Human Services. 541 Dietary guidelines for Americans. 7th Edition. Washington, DC: U.S. Government 542 Printing Office; December 2010

[2] Food Standards Agency. FSA nutrient and food based guidelines for UK institutions. 544 Accessed January 2012 www.food.gov.uk/multimedia/pdfs/nutguideuk.pdfz006. $\quad 545$

[3] Antova T, Pattenden S, Nikiforov B, Leonardi GS, Boeva B, Fletcher T, et al. Nutri- 546 tion and respiratory health in children in six Central and Eastern European coun- 547 tries. Thorax 2003:58:231-6.

[4] Maynard M, Gunnell D, Emmett P, Frankel S, Smith GD. Fruit, vegetables, and an- 549 tioxidants in childhood and risk of adult cancer: the Boyd Orr cohort. J Epidemiol 550 Community Health 2003:57:218-25.

[5] Wardle J, Carnell S, Cooke L. Parental control over feeding and children's fruit and 552 vegetable intake: how are they related? J Am Diet Assoc 2005;105:22

[6] Jahns L, Siega-Riz AM, Popkin BM. The increasing prevalence of snacking among 554 US children from 1977 to 1996. J Pediatr 2001;138:493-8.

[7] Ogden CL, Flegal KM, Carroll MD, Johnson CL. Prevalence and trends in overweight 556 among US children and adolescents, 1999-2000. J Am Med Assoc 2002;288: 557 1728-32.

[8] Ogden CL, Carroll MD, Curtin LR, Lamb MM, Flegal KM. Prevalence of high body 559 mass indề in U.S. cĥ̉ildren anâ adolescents, 2007-2008. J Am Med Assoc 560 2010;303(3):242-9.

[9] Guo SS, Chumlea WC. Tracking of body mass in children in relation to overweight 562 in adulthood. Am J Clin Nutr 1999;70:145S-8S.

10] Rosenstein D, Oster H. Differential facial responses to four basic tastes in new- 564 Dorns. Child Dev 1988:59:1555-68.

[11] Steiner JE. Facial expressions of the neonate infant indicating the hedonics of 566 1̂ood-related chemical stimuli. In: Weiffenbach JM, editor. Taste hedonics of 567 food-related chemical stimuli. Taste and development: the genesis of sweet pre- 568 ferenceWashington, DC: US Government Printing Office; 1977. p. 173-88.

[12]

[13] Desor J, Maller O, Greene LS. Preference for sweet in humans: infants, children, and 571 adults. In: Weiffenback JM, editor. Taste and development: the genesis of sweet pref- 572 erence. Washington, DC: US Government Printing Office; 1977. p. 161-73. 573

[14] Kaijura H, Cowart BJ, Beauchamp GK. Early developmental change in bitter taste 574 个esponses în human infants. Dev Psychobiol 1992;25:375-86. 575

[15] Pelchat ML, Pliner P. "Try it. You'll like it". Effects of information on willingness to 576 try novel foods. Appetite 1995; $24: 153-66$.

16] Pliner P, Hobden K. Development of a scale to measure the trait of food neophobia 578 in humans. Appetite 1992;19:105-20. 
[17] Cashdan E. A sensitive period for learning about food. Hum Nat 1994;5:279-91. 18] Nicklaus S, Boggio V, Chabanet C, Issanchou S. A prospective study of food variety seeking in childhood, adolescence and early adult life. Appetite 2005;44:289-97.

19] Cooke L, Carnell S, Wardle J. Food neophobia and mealtime food consumption in 4-5 year old children. Int J Behav Nutr Phys 2006:3:14.

[20] Koivisto UK, Sjoden PO. Food and general neophobia in Swedish families: parentchild comparisons and relationships with serving specific foods. Appetite 1996;26: $107-18$

[21] Skinner JD, Carruth BR, Bounds W, Ziegler PJ. Children's food preferences: a longitudinal analysis. J Am Diet Assoc 2002;102:1638-47.

22] Cooke L, Wardle J, Gibson EL. Relationship between parental report of food neophobia and everyday food consumption in 2-6-year-old-children. Appetite 2003;41:205-6.

[23] Birch LL, Marlin DW, Rotter J. Eating as the "means" activity in a contingency: effects on young children's food preference. Child Dev 1984;55:432-9.

24] Batsell W, Brown A, Ansfield M, Paschall G. "You Will Eat All of That!" A retrospective analysis of forced consumption episodes. Appetite 2002;38:211-9.

25] Fisher JO, Mitchell DC, Smiciklas-Wright H, Birch LL. Eat as I say and eat as I do: Parental influences on young girls' fruit and vegetable intake. J Am Diet Assoc 2002;102:58-64.

[26] Forestell CA, Mennella JA. Early determinants of fruit and vegetable acceptance. Pediatrics 2007:120:1247-54.

27] Birch LL, McPhee L, Shoba BC, Pirok E, Steinberg L. What kind of exposure reduces children's food neophobia? Looking vs. tasting. Appetite 1987;9:171-8.

28] Wardle J, Herrera ML, Cooke L, Gibson EL. Modifying children's food preferences: the effects of exposure and reward on acceptance of an unfamiliar vegetable. Eur J Clin Nutr 2003;57:341-8.

[29] Gerrish CJ, Mennella JA. Flavor variety enhances food acceptance in formula-fed infants. Am J Clin Nutr 2001:73:1080-5.

[30] Carruth B, Ziegler P, Gordon A, Barr S. Prevalence of picky eaters among infants and toddlers and their caregivers' decisions about offering a new food. J Am Diet Assoc 2004;104(1):57-64.

[31] Birch LL, Fisher J, Grimm-Thomas K. Children and food. In: Siegal M, Petereson CC, êditors. Ĉhildren's understanding of biology and health. Cambridge, England: Cambridge University Press; 1999. p. 161-82.

[32] Nguyen SP. An apple a day keeps the doctor away: children's evaluative categories of food. Appetite 2007;48:114-8.

[33] Wellman HM, Johnson CN. Children's understanding of food and its functions: a preliminary study of the development of concepts of nutrition. J Appl Dev Psycho 1982;3:135-48.

[34] Wardle J, Huon G. An experimental investigation of the influence of health information on children's taste preferences. Health Educ Res 2000;15:39-44.

[35] Heath PM, Houston-Price C, Kennedy OB. Can visual exposure impact on children's visual preferences for fruit and vegetables? Proc Nutr Soc 2010;69:E422.

[36] Houston-Price C, Butler L, Shiba P. Visual exposure impacts on toddlers' willingness to taste fruit and vegetables. Appetite 2009;53(3):450-3.
[37] Sears, W, Sears, M, \& Kelly, CW. Eat Healthy, Feel Great. New York: Little, Brown 626 and Company.

39] Pliner P, Loewen ER. Temperament and food neophobia in children and their 629 mothers. Appetite 1997:28:239-54. 630

[40] Birch LL, Fisher JO, Grimm-Thomas K, Markey CN, Sawyer R, Johnson SL. Confir- 631 matory factor analysis of the Child Feeding Questionnaire: a measure of parental 632 attitudes, beliefs and practices about child feeding and obesity proneness. Appe- 633 tite 2001:36:201-10.

[41] Mennella JA, Nicklaus S, Jagolino AL, Yourshaw LM. Variety is the spice of life: 635 strategies for promoting fruit and vegetable acceptance during infancy. Physiol 636 Behav 2008:94:29-38.

[42] Flaherty CF, Rowan GA. Successive, simultaneous, and anticipatory contrast in the 638 consumption of saccharin solutions. J Exp Psychol Anim Behav Process 1986;12: 639 381-93.

[43] Pliner P. The effects of mere exposure on liking for edible substances. Appetite 641 1982;3(3):283-90.

[44] Pliner P, Polivy J, Herman CP, Zakalusny I. Short-term intake of overweight indi- 643 viduals and normal weight dieters and non-dieters with and without choice 644 among a variety of foods. Appetite 1980;1:203-13.

[45] Birch LL, Fisher JO, Grimm-Thomas K, Markey CN, Sawyer R, Johnson SL. Confir- 646 matory factor analysis of the Child Feeding Questionnaire: a measure of parental 647 attitudes, beliefs and practices about child feeding and obesity proneness. Appe- 648 tite 2001;36:201-10. 649

[46] Clark HRE, Goyder P, Bissell Ł, Blank, Peters J. How do parents' child-feeding be- 650 Q7 haviours influence child weight? Implications for childhood obesity policy. J Pub- 651 lic Health 2007;29:132-41. 652

[47] Baughcum AES, Powers W, Johnson B, Chamberlin LA, Deeks CM, Jain A, et al. Ma- 653 ternal feeding practices and beliefs and their relationships to overweight in early 654 childhood. J Dev Behav Pediatr 2001;22:391-408.

[48] Webber L, Hill C, Cooke L, Carnell S, Wardle J. Associations between child weight 656 and maternal feeding styles are mediated by maternal perceptions and concerns. 657 Eur J Clin Nutr 2010;64:259-65.

[49] Dennison B, Rockwell H, Baker S. Fruit and vegetable intake in young children. 659 J Am Coll Nutr 1998; 17:371-8.

[50] Heath $\mathrm{P}$. Houston-Price $C$, Kennedy $\mathrm{OB}$. Increasing food familiarity without the 661 tears. A role for visual exposure? Appetite in press. 1121-6. 2] Singer MR, Moore LL, Garrahie EJ, Ellison RC. The tracking of nutrient intake in 666 young children: the Framingham Children's Study. Am J Public Health 1995;85: 667 $1673-7$.

[53] Must A, Jacques PF, Dallal GE, Bajema CJ, Dietz WH. Long-term morbidity and 669 mortality of overweight adolescents. A follow-up of the Harvard Growth Study 670 of 1922 to 1935. N Engl J Med 1992;327:1350-5. 